\title{
Bases conceituais e abordagens metodológicas sobre o processo de desertificação no Brasil
}

Conceptual bases and methodological approaches to the desertification process in Brazil

\author{
SILVA $^{1}$, I. A. S.; MARANHOLI ${ }^{2}$, H. N.; SILVA ${ }^{3}$, J. C. B.
}

ivamauro@hotmail.com

\begin{abstract}
Resumo
Este artigo tem como objetivo apresentar uma discussão teórica sobre o processo de desertificação no território brasileiro, almejando enfatizar os principais conceitos e abordagens metodológicas para o estudo deste processo. A pesquisa foi elaborada a partir da revisão bibliográfica com a contribuição de diferentes autores. Com a realização deste artigo, concluímos que a desertificação é um processo que se apresenta como vulnerável aos eventos climáticos, fenômeno que promove o desequilíbrio dos meios físico, biológico e socioeconômico, e um processo alvo de várias controvérsias entre os pesquisadores, devido à amplitude conceitual, ausência de uma abordagem integrada dos condicionantes, além da complexidade geoambiental e variabilidades climáticas regionais.
\end{abstract}

Palavras-chave: Desertificação; Conceitos; Metodologias.

\begin{abstract}
This article aims to present a theoretical discussion of the desertification process in Brazil, aiming to emphasize key concepts and methodological approaches to the study of this process. The research was drawn from the literature review with the contribution of different authors. With the completion of the article it concluded that desertification is a process that presents itself as vulnerable to climatic events, a phenomenon that promotes the imbalance of physical, biological and socio-economic means, and a target process several controversies among researchers due to the amplitude conceptual, lack of an integrated approach to conditioning, as well as geo-environmental complexity and regional climate variability.
\end{abstract}

Keywords: Desertification; Concepts; Methodologies.

\section{INTRODUÇÃO}

As pesquisas sobre a desertificação sempre foram associadas às preocupações mais amplas de ordem ecológica/ambiental e socioeconômica e nas últimas décadas, a temática ganhou destaque, constituindo-se um tema relevante, colocando a sociedade em alerta, perante aos processos erosivos, fenômenos climáticos e as perdas da capacidade produtiva das terras.

Portanto, nas últimas décadas, a temática desertificação ganhou destaque, constituindo-se um tema de primeira ordem, colocando a sociedade em alerta, perante os fenômenos climáticos, as perdas da capacidade produtiva das terras e a crise alimentar entre países ricos e subdesenvolvidos.

No Brasil, os problemas causados pelos eventos climáticos, sobretudo os relacionados à seca/estiagem atingem a região semiárida brasileira, desde os tempos do Império. Sales (2002, p. 117) afirma que "a partir da grande seca de 1877 , que o governo passou a considerar a seca como um problema nacional, pois a estiagem prolongada resultou na morte de milhares de nordestinos e marcaram as primeiras iniciativas oficiais de combate aos efeitos da seca”.

\footnotetext{
${ }^{1}$ Ivamauro Ailton de Sousa Silva, Doutorando em Geografia pelo Programa de Pós-Graduação em Geografia, Universidade Federal do Rio Grande do Sul, Porto Alegre-RS, Brasil.

${ }^{2}$ Henrique Nicolau Maranholi, Mestrando em Geografia pelo Programa de Pós-Graduação em Geografia, Universidade do Estado de Mato Grosso, Cáceres-MT

${ }^{3}$ Jeissy Conceição Bezerra da Silva, Mestranda em Geografia pelo Programa de Pós-Graduação em Geografia, Universidade Federal de Pernambuco, Recife-PE
} 
A partir desse acontecimento, deriva uma enorme produção teórica tanto literária quanto científica acerca dos problemas causados pelas estiagens que atingem frequentemente a região Nordeste brasileira (NEB).

Segundo Sales (2002 op. cit.), alguns dos trabalhos são clássicos, indispensáveis na análise e compreensão da forte relação do homem com a rusticidade do ambiente, incluindo-se "Os Sertões", de Euclides da Cunha, que analisa a influência do ambiente nas condições de vida do homem do sertão, constituindo-se em um dos mais ricos documentos que trata das relações entre ambiente e cultura no semiárido brasileiro.

Os primeiros pesquisadores a relatarem a problemática da desertificação no Brasil, foram Vasconcelos Sobrinho (1971), a quem se deve o mérito do pioneirismo nos estudos de desertificação no Brasil e posteriormente Ab'Saber (1977).

Além dos referidos autores, outros pesquisadores estudaram o fenômeno da desertificação e sua suscetibilidade no Nordeste brasileiro, tais como: Nimer (1980), Conti (1995), Matallo Junior (2001), Galvão (2001), Nascimento (2006), e Suertegaray (1992), lembrando que esta última realizou importantes estudos no Estado do Rio Grande do Sul, explicando através do conceito de arenização o processo de erosão do solo, aspecto físico característico do Sudoeste deste Estado.

A produção acadêmica sobre o tema compreendem os mais variados aspectos, analisados em diferentes espaços geográficos, escalas, metodologias e perspectivas. Assim, os referidos autores foram selecionados em função da boa divulgação e repercussão junto aos estudiosos do tema, sendo, portanto, fundamentais os estudos de âmbito regional e local.

Desta forma, este artigo tem como finalidade apresentar concepções teóricas pertinentes ao processo de desertificação no território brasileiro no âmbito dos estudos climáticos, mediante uma revisão literária de autores que trabalham ou trabalharam este conceito. Este artigo também levanta questões acerca dos estudos e propostas metodológicas que analisam a desertificação no território brasileiro.

\subsection{Desertificação: amplitude conceitual}

Existem diversos conceitos que enfoca o conceito de "desertificação". Para Vasconcelos Sobrinho (1978), a desertificação é um processo de fragilidade dos ecossistemas das terras secas em geral, decorrentes da pressão excessiva das populações humanas, perdem a produtividade e a capacidade de se recuperarem.

O geógrafo Ab'Saber (1977, p.1), define desertificação como "processos parciais, pontuais ou areolares, suficientemente radicais para designar degradações irreversíveis da paisagem e dos 
tecidos ecológicos naturais". Segundo ainda este autor, as feições de degradação pontuais no território brasileiro são de fácil reconhecimento, sobretudo nas paisagens sertanejas do Nordeste brasileiro, incluídas na categoria de verdadeiros Geótopos áridos.

Ab’Saber (1977, op. cit.), caracterizou as áreas suscetíveis à desertificação, de acordo com a predisposição da estrutura geoecológica, determinada, principalmente pelas deficiências hídricas sazonais, que em alguns setores associam-se às atividades humanas.

Para Nimer (1980), desertificação é a:

crescente degradação ambiental expressa pelo ressecamento e perda da capacidade de produção dos solos. Esse ressecamento crescente do meio natural pode ser uma decorrência da mudança do clima regional e ou do uso inadequado dos solos pelo homem (NIMER, 1980, p. 614).

Outra contribuição conceitual foi elaborada por Conti (1995), que define desertificação como processo e, portanto, dinâmica, estando, frequentemente, associado a períodos secos bastante longos, que apresentam alta variabilidade climática, constituindo regiões situadas em clima árido, semiárido e subúmido seco. O referido autor enfatiza três modalidades de desertificação (Quadro 1).

Quadro 1 - Tipos de desertificação

\begin{tabular}{|c|l|}
\hline Tipos de desertificação & \multicolumn{1}{|c|}{ Gênese/condicionantes e conceito } \\
\hline Biológica/Ecológica & $\begin{array}{l}\text { Quando os ecossistemas perdem sua capacidade de regeneração, verificando-se } \\
\text { rarefação da fauna e redução da superfície coberta por vegetação, seguidas de } \\
\text { empobrecimento dos solos e salinização. }\end{array}$ \\
\hline Climática & $\begin{array}{l}\text { redução progressiva das chuvas, determinada por causas naturais, como por exemplo: } \\
\text { alterações na atividade solar, mudança na temperatura de águas oceânicas, fenômenos } \\
\text { geológicos. }\end{array}$ \\
\hline Antrópica & $\begin{array}{l}\text { extensão das paisagens tipicamente desérticas em áreas semiáridas ou subúmidas } \\
\text { decorrentes da retirada e exploração predatória em grande escala dos recursos naturais. }\end{array}$ \\
\hline
\end{tabular}
Elaboração: Ivamauro Ailton de Sousa Silva. Fonte: CONTI, 1995.

A Convenção das Nações Unidas para o Combate à Desertificação (UNCCD), conceitua a desertificação como o processo de degradação das terras das regiões áridas, semiáridas e subúmidas secas, resultantes de fatores diversos tais como as variações climáticas e derivações antropogênicas (BRASIL, 1999).

Conforme Suertegaray et. al. (2001), o processo de desertificação é reservado para expressar a degradação do solo, vegetação e água em condições climáticas adequadas, bem como períodos secos prolongados, baixos índices pluviométricos e presença de aridez.

Assim, a ocorrência da desertificação é considerada restrita aos ambientes áridos, semiáridos e subúmidos secos, que naturalmente apresentam fragilidade ambiental e limitadas condições de autocontrole ou autorecuperação, frente à instalação de processos transformadores. 
Os conceitos encontrados na literatura indicam que o processo de desertificação apresenta a derivação antropogênica como primordial em seu desencadeamento. Todavia, Conti (1995, p. 49), enfatiza que o processo pode ser compreendido como "uma mudança climática desencadeada por causas naturais que é de uma escala cronológica muito mais ampla que a humana, interessando, portanto a estudos geológicos e paleoclimáticos".

Sales (2002), enfatiza que as causas da desertificação geram muitas controvérsias e que as variações climáticas assumem uma importância maior do que as relacionadas às atividades humanas nos processos de degradação ambiental.

\section{METODOLOGIA}

Nos dias atuais é bem reconhecida a importância das pesquisas em Geografia que envolvem estudos sobre processos de degradação ambiental, na construção de novos parâmetros conceituais e metodológicos para abordar e elucidar os processos que atuam na paisagem e as relações existentes no espaço geográfico.

Diante dos desafios metodológicos, enfrentados no desenvolvimento desta pesquisa, foi fundamental uma ampla e profunda revisão bibliográfica para a aquisição de bases teóricas da pesquisa, no qual, destinou-se apresentar as abordagens conceituais e perspectivas metodológicas acerca do processo de desertificação no território brasileiro.

\section{RESULTADOS E DISCUSSÃO}

\subsection{Desertificação: o debate sobre as questões metodológicas}

A desertificação ainda é considerada um processo precariamente caracterizado e mal dimensionado, devido à complexidade dos conceitos, parâmetros e métodos de análise. Desta forma, Matallo Junior (2001), enfatiza que os aspectos teóricos e metodológicos têm sido motivo de infindáveis controvérsias e questionamentos, que impõe restrições decisivas para compreender o processo de desertificação.

A Convenção das Nações Unidas para o Combate à Desertificação (UNCCD), representou um ponto de ruptura com o plano conceitual e metodológico dos estudos de desertificação, que priorizava o suporte físico em detrimento dos aspectos sociais e econômicos.

\subsection{Parâmetros de análise, escalas e limitações}

De acordo com Gomes (2009), a utilização de escalas compatíveis, o recorte, a espacialidade e temporalidade, as categorias de análise e a integração de condicionantes (fatores), oferecem 
subsídio que possibilitam compreender fenômenos/processos que atuam na superfície terrestre. O referido autor também tem a preocupação em definir os conceitos e justificar os recortes. Assim, corrobora que o recorte é um instrumento relevante para que determinada análise de um processo/fenômeno não sofra generalizações.

Para Moreira (2007, p.116) “o recorte faz parte da elucidação do espaço que é palco de transformações, gênese de processos, uma expressão direta que combina princípios de localização e distribuição". Assim, a escala é um complexo entrecortado de domínios de um território, e espacialidade que possibilita perceber um fenômeno em sua dimensão geográfica, por meio da localização, distribuição e conexão, e isso permite delimitar a extensão e verificar a escala de sua manifestação na paisagem.

Para a análise do processo de desertificação, Nascimento (2006) fundamenta o enfoque sistêmico com base nos seguintes procedimentos:

a) diagnosticar os componentes geoambientais, em termos de potencialidades e limitações;

b) elaborar mapeamentos básicos e temáticos pertinentes às questões ambientais;

c) favorece a prospecção de áreas degradadas considerando o balanço morfogênese versus pedogênese das paisagens dos geoambientes;

d) permite a avaliação das principais causas e consequências ambientais dos processos de degradação que podem desencadear a desertificação, com ênfase nos agentes produtores do espaço e atividades produtivas.

Para avaliar o processo de desertificação, diversos autores elaboraram metodologias, pautadas, sobretudo em indicadores, procedimentos (etapas), métodos de análise, escalas, entre outros. Nota-se que a maioria das pesquisas que abordam a temática, refere-se ao diagnóstico do estado atual da desertificação, abstraindo a análise temporal dos processos. Ao realizar o resgate histórico do processo, isso oferece uma nova abordagem, considerando as contribuições da História ambiental para entender esses processos e articular em um sistema integrado.

Galvão (2001), afirma que este procedimento tem como objetivo articular a dimensão espacial e temporal por meio de diferentes contribuições da Geografia e da História, através da identificação e reconstrução das condições geoambientais pretéritas e as marcas iniciais do uso e ocupação das terras. Neste sentido, a obtenção de registros históricos e arqueológicos, podem fornecer dados sobre o estado ambiental do passado.

A conferência dos registros históricos (documentos de origem, narrativas de viajantes, etc.) relacionados com ambiente, corrobora para a hipótese sobre as mudanças que ocorreram entre a situação atual e a base do ecossistema, visto que as paisagens naturais são combinações complexas que constituem e situam para o plano histórico na escala cronológica. Assim, inicia-se o processo 
de comparação entre o estado e a tendência dos indicadores selecionados para o estudo dos processos de mudança produzidos no meio ambiente, pela derivação natural ou antropogênica.

A desertificação como um processo dinâmico, conforme elucida Nascimento (2006), deve ser verificada e avaliada por meio de indicadores em análises comparativas, da seguinte forma: a) comparação de uma área em diferentes épocas; e, b) comparação das condições em duas áreas distintas na mesma época.

Outro procedimento foi elaborado por Conti (1995), que propõe a metodologia estatística de estudos das séries temporais, aplicada aos dados de precipitação pluviométrica, com o objetivo de encontrar tendências, ciclicidades e indicadores da variabilidade interanual.

Nimer (1980), propõe uma metodologia pautada em três eixos: climatológico, geomorfológico e pedológico. O resultado deste estudo teria como produto a elaboração de cartas temáticas que, superpostas, permitiriam conhecer os diferentes níveis de riscos à desertificação.

Para determinar a suscetibilidade que determinada região tem ao processo de desertificação, a UNCCD considera as zonas áridas, semiáridas e subúmidas secas todas as áreas com exceção das polares e das subpolares, com Índice de Aridez (IA) entre 0,05 e 0,65.

Atualmente, o índice de aridez serve como parâmetro mundial, e é estimado pelo quociente entre a quantidade de precipitação média anual (P) e a perda máxima possível de água por meio da evapotranspiração potencial total anual (ETP). Os tipos de clima com suas respectivas amplitudes de aridez são apresentados no quadro 2.

Quadro 2 - Tipos de clima segundo a amplitude de variação do Índice de Aridez (P/ETP).

\begin{tabular}{|c|c|}
\hline Zonas climáticas & Amplitude do Índice de Aridez \\
\hline Hiper-árido & $<0,005$ \\
\hline Árido & $0,05-0,20$ \\
\hline Semi-árido & $0,21-0,50$ \\
\hline Subumido Seco & $0,51-0,65$ \\
\hline Subumido e Úmido & $>0,65$ \\
\hline \multicolumn{2}{|c|}{} \\
\hline
\end{tabular}

Conforme o quadro 1, observa-se que as áreas susceptíveis à desertificação no Brasil estão localizadas na região Nordeste, com predomínio de climas semiáridos e subúmidos secos, com Índice de Aridez variando entre 0,21 a 0,65. Estas regiões têm em comum o fato de serem caracterizadas pela ausência, escassez, quantidade limitada e, ainda, pela distribuição irregular das precipitações pluviométricas, associadas a elevadas taxas de evaporação. 


\subsection{Propostas Metodológicas Pautadas em Indicadores}

Vasconcelos Sobrinho (1978), ao estudar as áreas suscetíveis à desertificação (ASD), selecionou empiricamente, áreas pilotos, onde existiam intensos processos de degradação de solo e da cobertura vegetal no Nordeste brasileiro. O referido autor relacionou os indicadores a serem considerados na desertificação (físicos, biológicos, sociais, uso da terra e processos sociais) e estabeleceu, ainda, o conceito de áreas-parâmetro como recobertas de vegetação primitiva, contíguas às que ocorrem desertificações (áreas-piloto), permitindo comparar a evolução deste fenômeno.

As áreas selecionadas por Vasconcelos Sobrinho (1978, Op. Cit), foram caracterizadas como de alto risco à desertificação e foram designadas de Núcleos de Desertificação, descritas como áreas em que a degradação da cobertura vegetal e do solo alcançou uma condição de irreversibilidade. Ainda o referido autor, indicou os núcleos existentes do Nordeste brasileiro e aponta os espaços geográficos mais problemáticos e potenciais à desertificação: Gilbués-PI; Irauçuba-CE; Região do Seridó Norteriograndense-RN; e Cabrobró-PE, reconhecidas e caracterizadas até hoje pela literatura (Figura 1).

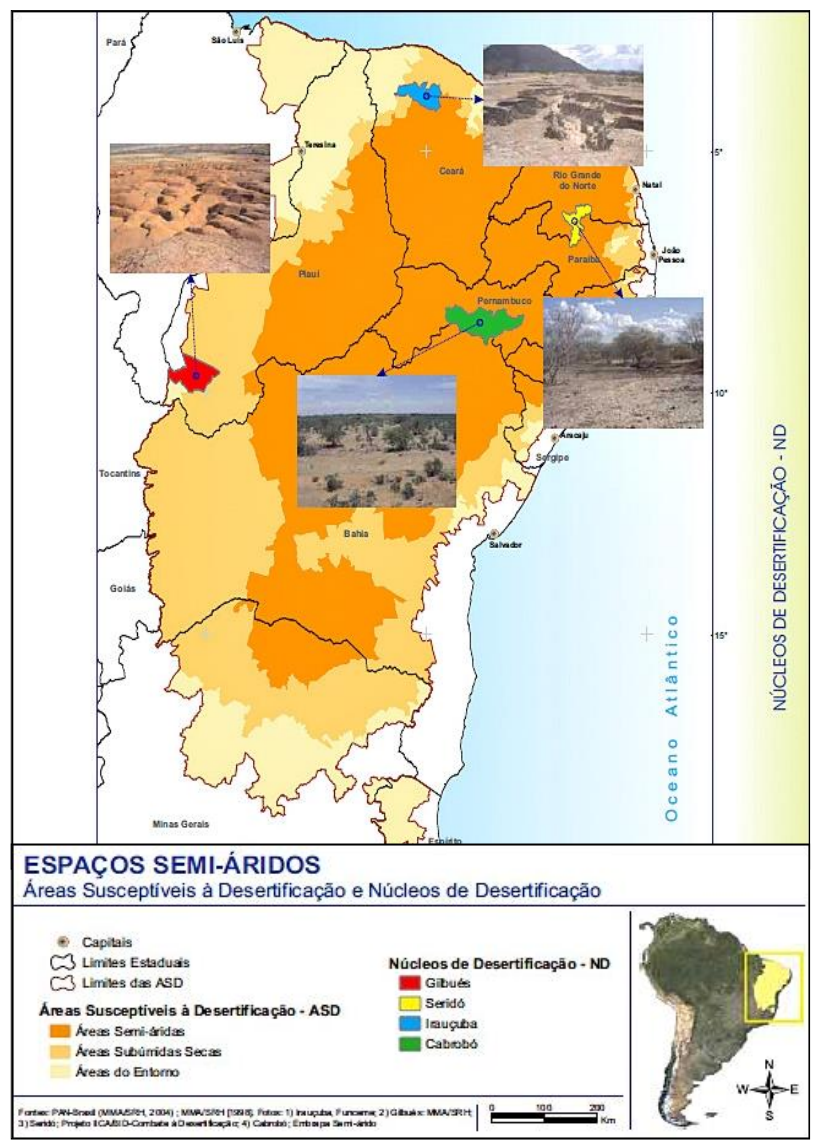

Figura 1 - Mapa das áreas suscetíveis à desertificação e os núcleos. Fonte: BRASIL, 2004 
Todos os núcleos de desertificação estão localizadas no Nordeste brasileiro, em clima semiárido e sob o embasamento geológico cristalino, com exceção do núcleo de Gilbués-PI, que predomina clima subúmido, assentado em litologia sedimentar.

Com o propósito de uniformizar os procedimentos de identificação e monitoramento dos processos de desertificação, Matallo Junior (2001), propôs uma extensa e criteriosa metodologia que agrupa os indicadores em dois grandes grupos: situação (sociais, econômicos e climáticos) e desertificação (índices de vegetação, solos e recursos hídricos). Esta classificação representa um marco referencial de consenso entre os pesquisadores da atualidade.

Vasconcelos Sobrinho (1983), elucida que a identificação de indicadores proporciona melhor conhecimento do desencadeamento do processo de desertificação, permite avaliar a vulnerabilidade da área, prever o começo da desertificação, monitorar o processo nas áreas e avaliar as consequências do processo de desertificação, e assim fornecer subsídios para minimizar seus efeitos.

De acordo com Nascimento (2006), o conjunto de indicadores de desertificação, fornecem uma base fundamental para a compreensão de como os fatores (físicos e socioeconômicos) atuam no desenvolvimento do processo. Neste sentido, é indispensável uniformizar as abordagens conceituais e metodológicas que consideram o contexto local específico, priorizando os aspectos físicos.

Desta forma, os indicadores permitem efetuar critérios como escala (recorte espacial e temporal), que permite combinar tendências na evolução de uma situação ambiental em uma área. Portanto, os indicadores, representam um instrumento sintético, transmissor de informações de maneira significativa, decodificam estados do meio ambiente, considerando o contexto dinâmico da natureza.

\section{CONSIDERAÇÕES FINAIS}

O processo de desertificação, que tem como causa as variações climáticas e as ações antrópicas, exemplificam a necessidade da abordagem geossistêmica para a compreensão das relações e inter-relações que se estabelecem nas regiões áridas, semiáridas e subúmidas secas, sujeitas a este processo que envolve diferentes metodologias de estudo.

$\mathrm{O}$ arquétipo metodológico proposto nesta pesquisa (abordagem geossistêmica e indicadores), pode ser utilizado em escalas locais e regionais. Metodologicamente, a abordagem sistêmica é de difícil realização, pois exige um trabalho de equipe interdisciplinar, com domínio sobre variados campos do conhecimento. 
O enfoque geossistêmico deve ser abordado pressupondo-se a interação dos fenômenos naturais a partir da troca de fluxos energéticos, de matéria e de informação, correspondentes à teia interativa dos componentes naturais com os sociais em suas múltiplas e complexas relações.

Já a proposta metodológica pautada em indicadores pode facilitar a compreensão das causas e evolução do processo de desertificação, pois necessitará definir uma escala (espacial e temporal) adequada, determinar as condições atuais considerando especialmente a complexidade e a interação entre as condições ou fatores ambientais e socioeconômicos.

O índice de aridez é outro procedimento importante para os estudos de desertificação, do ponto de vista climático, serve como parâmetro mundial para as classificações de áreas susceptíveis à desertificação.

Nesse sentido, considerando a complexidade do processo de desertificação, acredita-se que o enfoque sistêmico apresenta-se relevante para os estudos que envolvem processos da paisagem evidenciando, sobretudo os fatores condicionantes que acarretam transformações e alteram o meio ambiente, para a melhor compreensão dos fenômenos de degradação ambiental que vêm ocorrendo, principalmente na região Nordeste do Brasil.

\section{REFERÊNCIAS}

AB'SABER, A. N. Problemática da desertificação e da savanização no Brasil intertropical. Geomorfologia, 53. São Paulo: Instituto de Geografia. 1977.

BRASIL, GOVERNO DO. Desertificação - III Conferência das Partes da Convenção das Nações Unidas. Brasília: Ministério do Meio Ambiente/Prática, 1999. 23 p.

BRASIL, GOVERNO DO. Programa de ação nacional de combate à desertificação e mitigação dos efeitos da seca - PAN-Brasil. Brasília, DF: Ministério do Meio Ambiente. Secretaria de Recursos Hídricos, 2004. 242p

CONTI, J. B. Desertificação nos trópicos. Proposta de metodologia de estudo aplicada ao Nordeste Brasileiro. 1995. Tese de Livre Docência apresentada na Faculdade de Filosofia, Letras e Ciências Humanas da USP, São Paulo, 1995.

GALVÃO, A. L. C. O. Reconhecimento da susceptibilidade ao desenvolvimento de processos de desertificação no nordeste brasileiro, a partir da integração de indicadores ambientais. Brasilia, UnB. Tese de Doutorado apresentada no Programa de Pós-Graduação em Geografia da Universidade de Brasília-UnB, 2001. 298 p.

GOMES, P. C. C. Um lugar para a Geografia: contra o simples, o banal e o Doutrinário. In: MENDONÇA, F. A; SAHR, C. L. L e SILVA, M. da (org). Espaço e Tempo: complexidade e desafios do pensar e do fazer Geográfico. Curitiba-PR: ADEMADAN, 2009. 18p.

MATALLO JÚNIOR, H. Indicadores de desertificação: histórico e perspectivas. Brasília, UNESCO, 2001. 126 p. 
MOREIRA, Ruy. Pensar e ser em Geografia: ensaios de história, epistemologia e ontologia do espaço Geográfico. São Paulo: Contexto, 2007.

NASCIMENTO, F. R. Degradação ambiental e desertificação no Nordeste Brasileiro: o contexto da Bacia Hidrográfica do rio Acaraú - CE. (Tese de doutorado em Geografia). Instituto de Geociências, UFF: Niterói, 2006. 325 p.

NIMER, E. Subsídios ao Plano de Ação Mundial para Combater a Desertificação: Programa das Nações Unidas para o Meio Ambiente (PNUMA). Revista Brasileira de Geografia, Rio de Janeiro, v. 42, nº 3, 1980. p.: 612-637.

SALES, M. C. L. Evolução dos estudos de desertificação no Nordeste Brasileiro. GEOUSP: Espaço e Tempo, 11, 2002, p.115-126.

SUERTEGARAY, D. M. A. Deserto Grande do Sul: Controvérsia. Porto Alegre: Editora da Universidade, UFRGS, 1992.

SUERTEGARAY, D. M. A. et. al. Atlas da arenização - Sudoeste do Rio Grande do Sul. Porto Alegre/RS: Secretaria da Coordenação e Planejamento, 2001. 85 p.

VASCONCELOS SOBRINHO, J. Núcleos de desertificação no polígono das secas - nota prévia. In: ICB - UFPE, 1971, p. 69-73.

Metodologia para identificação de processos de desertificação: manual de indicadores. Recife: SUDENE, 1978. 18 p.

Processos de desertificação ocorrentes no Nordeste do Brasil: sua gênese e sua contenção. Recife: SUDENE, 1983. 101 p.

\section{AGRADECIMENTO}

Os autores agradecem a Coordenação de Aperfeiçoamento de Pessoal de Nível Superior (CAPES) pela atual concessão de bolsa no curso de Doutorado (UFRGS) e Mestrado (UNEMAT e UFPE).

Recebido em: 14/08/2016

Aceito para publicação em: 01/10/2016 